\title{
Study of Right Marginal Artery in Post Mortem Hearts of Adult Bangladeshi People
}

\author{
A Hossain ${ }^{1}$, A Ara $^{2}$, S Ara $^{1}$ \\ ${ }^{1}$ Department of Anatomy, DMCH, Dhaka. ${ }^{2}$ Department of Anatomy, Ibn Sina Medical College, Dhaka
}

\begin{abstract}
Key words:

Background: Heart disease is one of the major public health problems in Bangladesh. Treatment of Postmortem

heart, Coronary arteries, Right marginal artery. heart disease is costly \& complex issue. The study of anatomy of the right marginal artery is essential for the proper diagnosis and treatment of the heart diseases.

Materials: The study was carried out in the Department of Anatomy, Dhaka Medical College (DMC), Dhaka from February 2005 to January 2006. Post mortem study of sixty (60) adult human hearts of Bangladeshi people aging from 20 to 75 years was performed. The samples were divided into 3 age groups - Group A (20 to 40 years) consists of 35 males \& 7 female, Group B (41 to 60 years) consists of 8 male \& 3 female and Group $C$ (61 to 75 years) consists of 7 male. All the samples of different age groups were examined morphologically.

Results: In the present study, the right marginal artery was present in 54 and absent in 6 , out of 60 samples. Out of 54, the right marginal artery was terminated at the apex in 15 and nearer to the apex in 39 cases.

Conclusion: The result of the present study can be helpful to the cardiologists and cardiovascular surgeons for proper anatomical assessment of coronary arteries in patients with heart diseases.
\end{abstract}

(Cardiovasc. j. 2009; 1(2) : 165-168)

\section{Introduction}

Cardiovascular diseases a major concern of the people suffering from the diseases as well as of the people related to the health care delivery systems. Considerable decline in the mortality from Ischaemic heart disease or Stroke is noticed in recent times, by bringing about changes in dietary habits and lifestyles, better control of hypertension, recent rapid advances in medical \& surgical management and advanced diagnostic technology and better health care delivery system ${ }^{1}$.

When we talk about cardiovascular disease, the disease that comes into our mind is ischaemic heart disease (IHD) or coronary heart disease (CHD). This is because of sudden and unexpected fatal consequence; it can produce in an otherwise healthy-looking individual. In 90 percent of cases, the cause of Ischaemic heart disease is reduction in coronary blood flow due to atherosclerosis. Atherosclerosis is a silent disorder that begins in the childhood. Intimal lesions have been found as early as 9 months of age. The disease process of the coronary arteries can proceed to an advanced stage before any symptoms are produced ${ }^{2}$.

In the United Kingdom, almost 50 percent of all deaths are attributable to cardiovascular disease, and of these, at least 50 percent are due to CHD. Heart disease is a predominant cause of death and disability in the western affluent industrialized nations. There, it is the commonest cause of death from the $4^{\text {th }}$ decade onwards of life. In the United States, atherosclerosis-related CHD results almost 65,000 fatalities annually. It is noticed with concern that the incidence of coronary heart disease is increasing in the developing countries of South Asia and in Bangladesh ${ }^{3}$.

Atherosclerotic related vascular lesions, once produced in the human, cannot be reverted to normal. But atherosclerosis could be inhibited to some extent if preventive measures are taken early. Significant risk factors that predisposes to atherosclerosis are : (a) hyperlipidaemia, (b) hypertension, (c) cigarette smoking and (d) diabetes. These factors vary obviously among populations. Racial and geographic variations in the incidence of aortic and coronary atherosclerosis have also been reported ${ }^{4}$.

Recent advances in cardiac surgery and the search for new techniques toward investigation of the heart are demanding a review of the anatomy of the coronary arteries and their branches to provide an updated background for practical

Address of correspondence: Dr Asad Hossain, Assistant Professor of Anatomy, Dhaka Medical College, Dhaka, Bangladesh 
application. Before trying on sophisticated studies of coronary microcirculation, some basic anatomical studies should be carried out on the heart of Bangladeshi People ${ }^{5}$.

\section{Materials and methods:}

The present study was performed on sixty (60) postmortem adult human hearts of Bangladeshi people of both sexes. Among them, fifty (50) were male aging from 20 to 75 years and ten (10) were female aging from 20 to 55 years. The samples were divided into three groups (Table-1). All the samples were studied gross morphologically by careful dissection.

The samples for the study were collected from the morgue of the Department of Forensic Medicine of Dhaka Medical College from April 2005 to December 2005. After requisite legal formalities, the samples were collected from unclaimed dead bodies as early as possible, before any sign of putrefaction developed. The sample were washed thoroughly with tap water and gently squeezed to remove the blood clots from the cavity of the heart and from the lumen of the blood vessels as much as possible. Then the sample was brought to the Department of Anatomy of DMC. In the dissection room, the hearts were cleaned by removing all fat and other associated tissue from the surface of the heart. Then the hearts were preserved in $10 \%$ formol saline solution.

\section{Table-I}

Age distribution in different group

\begin{tabular}{lccc}
\hline Group & Age range (years) & Male & Female \\
\hline A & 20 to 40 & 35 & 7 \\
B & 41 to 60 & 8 & 3 \\
C & 61 to 75 & 7 & 0 \\
\hline
\end{tabular}

The formol saline fixed samples were kept in the tap water to wash out the formol saline so as to minimize the irritation of the eyes and also for somewhat softening of the fixed tissue. Then the sample was taken in a tray and with the help of scissors and toothed dissecting forceps, the pericardium, fat and other unwanted tissues were removed carefully so that the heart was exposed properly.

\section{Measurement procedures:}

The right marginal artery:

The right marginal artery was observed from its origin whether it arose from the right coronary artery or absent. It was also observed for its termination whether it was at the apex or nearer to the apex (Fig. No.1\&2).

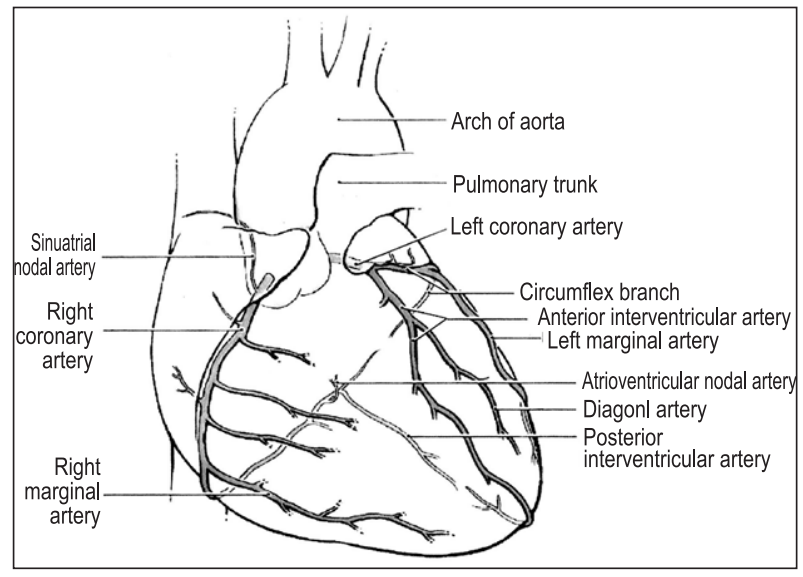

Fig.-1: Anterior view of coronary arteries (From Agur, 2005)

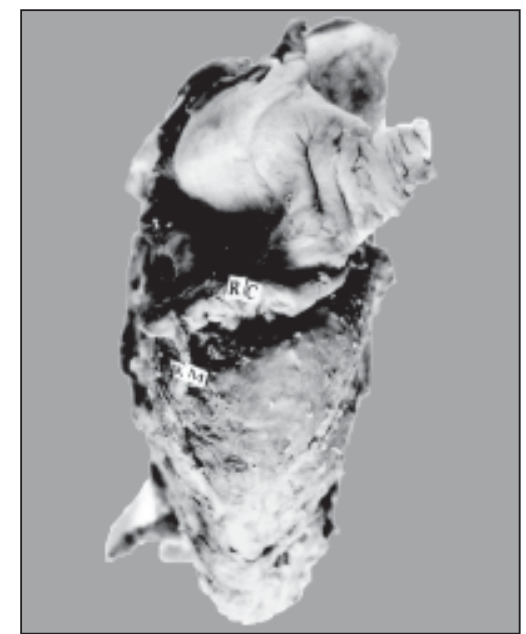

Fig.-2: Photograph showing the right marginal artery (RC-Right coronary artery, RM-Right marginal artery).

\section{Statistical processing of data:}

Appropriate Statistical Package for Social Science (SPSS), such as, Chi-square test, to evaluate significance of variance of the different findings were done.

\section{Results:}

The present study was performed on sixty (60) adult postmortem human hearts of Bangladeshi people. Among them fifty (50) were males aging from 20 to 75 years and ten (10) were female's aging from 20 to 55 years. All the samples were divided into 3 age groups: Group A (20 to 40 years), Group B (41 to 60 years) and Group C (61 to 75 years). All the samples were studied gross morphologically.

\section{Existence of the right marginal artery}

In-group $\mathrm{A}$, the right marginal artery was present in $32(91.4 \%)$ and absent in $3(8.6 \%)$ in male and in 
female was present in $6(85.7 \%)$ and absent in 1 (14.3\%) samples. In-group B, the right marginal artery was present in 7 (87.5\%) and absent in 1 $(12.5 \%)$ in male and in female was present in 3 (100\%) samples. In-group C, the right marginal artery was present in $6(85.7 \%)$ and absent in 1 $(14.3 \%)$ in male samples. Statistical analysis between sex did not show any significant difference $(\mathrm{P}>0.50, \mathrm{P}>0.10)$ [Table 2, Fig.1\&2].

Site of termination of the right marginal artery: In-group A, the right marginal artery was terminated at the apex in $9(28.1 \%) \&$ nearer to the apex in $23(71.9 \%)$ in male and in female was terminated at the apex in $1(16.7 \%)$ \& nearer to the apex in $5(83.3 \%)$ samples. In-group B, the right marginal artery was terminated at the apex in 2 $(28.6 \%)$ \& nearer to the apex in $5(71.4 \%)$ in male and in female was terminated at the apex in 1 (33.3\%) \& nearer to the apex in $2(66.7 \%)$ samples. In-group $\mathrm{C}$, the right marginal artery was terminated at the apex in $2(33.3 \%) \&$ nearer to the apex in $4(66.7 \%)$ in male samples. Statistical analysis between sex did not show any significant difference ( $\mathrm{P}>0.50, \mathrm{P}>0.50)$, [Table 3, Fig.1\&2].

Table-II

Existence of right marginal artery $(n=60)$

\begin{tabular}{|c|c|c|c|c|c|c|}
\hline \multirow[t]{2}{*}{ Group } & \multirow[t]{2}{*}{$\mathrm{n}$} & \multicolumn{2}{|c|}{ Present } & \multicolumn{2}{|c|}{ Absent } & \multirow[t]{2}{*}{ Pvalue } \\
\hline & & No. & $\overline{(\%)}$ & $\overline{\text { No. }}$ & $(\%)$ & \\
\hline \multicolumn{7}{|l|}{$\overline{\text { Male }}$} \\
\hline A & 35 & 32 & (91.4) & 3 & (8.6) & \multirow{3}{*}{$>0.50^{\mathrm{ns}}$} \\
\hline B & 8 & 7 & (87.5) & 1 & (12.5) & \\
\hline $\mathrm{C}$ & 7 & 6 & (85.7) & 1 & (14.3) & \\
\hline \multicolumn{7}{|c|}{ Female } \\
\hline A & 7 & 6 & (85.7) & 1 & (14.3) & \multirow[b]{2}{*}{$>0.10^{\mathrm{ns}}$} \\
\hline B & 3 & 3 & $(100.0)$ & 0 & & \\
\hline
\end{tabular}

Statistical analysis done by Chi square test

Group A : Age 2040 years

Group B : Age 4160 years

Group C : Age 6175 years

ns $=$ Not significant

Table-III

Site of termination of right marginal artery $(n=60)$

\begin{tabular}{|c|c|c|c|c|c|c|}
\hline \multirow{3}{*}{ Group } & \multirow{3}{*}{$\mathrm{n}$} & & & \multicolumn{2}{|c|}{ Nearer } & \multirow{3}{*}{ Pvalue } \\
\hline & & \multicolumn{2}{|c|}{ At the apex } & \multicolumn{2}{|c|}{ To the apex } & \\
\hline & & No. & $(\%)$ & No. & $(\%)$ & \\
\hline \multicolumn{7}{|l|}{ Male } \\
\hline A & 32 & 9 & (28.1) & 23 & (71.9) & \multirow{3}{*}{$>0.50^{\mathrm{ns}}$} \\
\hline B & 7 & 2 & $(28.6)$ & 5 & (71.4) & \\
\hline $\mathrm{C}$ & 6 & 2 & (33.3) & 4 & (66.7) & \\
\hline \multicolumn{7}{|c|}{ Female } \\
\hline A & 6 & 1 & $(16.7)$ & 5 & (83.3) & \multirow[b]{2}{*}{$>0.50^{\mathrm{ns}}$} \\
\hline $\mathrm{B}$ & 3 & 1 & $(329)$ & $?$ & $(667)$ & \\
\hline
\end{tabular}

Statistical analysis done by Chi square test

Group A : $\quad$ Age 2040 years

Group B : : Age 4160 years

Group C : $\quad$ Age 6175 years

$\mathrm{ns}=$ Not significant 


\section{Discussion}

The present study was performed on sixty (60) adult postmortem human hearts of Bangladeshi people. Among them fifty (50) were male aging from 20 to 75 years and ten (10) were female aging from 20 to 55 years. All the samples were divided into 3 age groups: Group A (20 to 40 years), Group B (41 to 60 years) and Group C (61 to 75 years). All the samples were studied gross morphologically.

In the present study, the right margin artery was present for male in-group A, B, C was 32(91.4\%), $7(87.5 \%), 6(85.7 \%) \%)$, respectively and for female was $6(85.7 \%), 3(100 \%)$, respectively and absent for male in-group A, B, C was 3(8.6\%), 1(12.5\%), 1(14.3\%), respectively and for female was $1(14.3 \%)$. In the Bangladeshi peoples, Sarker examined 54 samples and found the right marginal artery was present in about $91 \%$ and absents in about $9 \%$ cases. Here, the values of the present study were somewhat similar to the values in the study of Sarker. ${ }^{2}$

The right marginal artery was terminated at the apex for male in-group A, B, C were $9(28.1 \%)$, $2(28.6 \%), 2(33.3 \%)$, respectively and for female were $1(16.7 \%), 1(33.3 \%)$, respectively and nearer to the apex for male in-group A, B, C were $23(71.9 \%), 5(71.4 \%), 4(66.7 \%)$, respectively and for female were 5(83.3\%), 2(66.7\%), respectively.

In the Bangladeshi peoples, Sarker examined 54 samples and found the right marginal artery was terminated at the apex $29.63 \%$ and nearer to the apex $61.11 \% .^{2}$ Here, the values in site of termination of the right marginal artery at the apex of the present study were somewhat similar and nearer to the apex were higher to the values in the study of Sarker. Rahman examined 70 adult human hearts and found the artery in $92.85 \%$ cases of which $52.85 \%$ reached the apex and $40 \%$ nearer to the apex in Bangladeshi people. ${ }^{3}$ Here, the values in site of termination of the right marginal artery at the apex of the present study were lower and nearer to the apex were higher to the values in the study of Rahman.

Crainicianu (1922, cited by Baroldi and Scomazzoni, 1967) found the artery in $95 \%$ cases of which $65 \%$ reached the apex. ${ }^{12}$ Mouchet (1933, cited by Baroldi and Scomazzoni, 1967) found the artery in $92 \%$ cases of which 55\% reached the apex. Gross (1921, cited by Baroldi and Scomazzoni, 1967) found the artery in $94 \%$ cases. Baroldi and Scomazzoni (1967) found this artery in $100 \%$ cases of which $93 \%$ reached the apex and $7 \%$ fell short of the apex (nearer to the apex).

\section{Conclusions:}

A descriptive postmortem study like the present study can give an overview about the anatomy of the coronary arteries of the Bangladeshi people. However, large sample size is very important in such epidemiological studies. Routine autopsy studies of hospital deaths should be encouraged. Study on living population, including patients of heart diseases, are also important, where various types of investigations like coronary angiogram \& CT angiogram may be applied. These findings may then be correlated with postmortem study results in developing a comprehensive epidemiological data pool. These data may be helpful in planning research.

Due to limitation of resources all age groups were not included. Sample size was small. Resin corrosive casts and angiography was not done in present study. Further studies with large sample size with wider age group using Resin corrosive cast and angiography are recommended.

\section{Reference:}

1. Islam S. M. Postmortem study of atherosclerosis in the aorta and coronary arteries in Bangladeshi males (Thesis), Dhaka:University of Dhaka; 1996, 2-6.

2. Sarker MSA. An anatomical study of the coronary arteries and the arch of the aorta in adult Bangladeshi people (Thesis), Dhaka : University of Dhaka; 1996, 12-65

3. Rahman ASMH. Anatomy of coronary circulation and dimensions of adult postmortem human hearts in Bangladesh (Thesis), University of Dhaka; 1989, 5-38.

4) Begum J. An anatomical study of atrio-ventricular valves, muscular part of interventricular septum and papillary muscle of the heart among the adult Bangladeshi people (Thesis), University of Dhaka; 1996, 2-57.

5. Moore KL, Dalley AF, editors. Clinically Oriented Anatomy. 5th ed. Baltimore: Lippincott Wiliams \& Wilkins; 2006. 120-39.

6. Agur AMR, Lee MJ, editors. Grant's Atlas of Anatomy. $11^{\text {th }}$ ed. Baltimore: Lippincott Williams \& Wilkins; 2005. 48-65.

7. Datta AK, editor. Essentials of Human Anatomy (Thorax and Abdomen) part 1.6th ed (Reprint). Calcutta: Current Books International; 2005. 49-83.

8. Hamilton N'J. editor. Textbook of Human Anatomy. 2" ed (Report). London: Macmillan Publishers Ltd; 1984. 201-41.

9. Giorgio Gabella. Cardiovascular System. In : Williams PL, Bannister LH, Berry MM, Collins P, Dyson M, Dussek JE, et al, editors. Gray's Anatomy : The Anatomical Basis of Medicine and Surgery. $39^{\text {th }}$ ed. Edinburgh: Churchill Livingstone; 2005. 995-1055.

11. Coronary circulation - Wikipedia, the free encyclopedia, GNU Free Docmentation License 2008:1-3 http.// enwikipedia.org/wiki/coronary_circulation.

12. Baroldi G, Mantero O, Scomazzoni G. The collaterals of the coronary arteries in normal and pathologic hearts. Cire Res 1956; 4: 223- 9. 